\title{
Self-Report of Emotional Abilities and Subjective Quality of Life Among Physical Education Teachers
}

\author{
Audronė Dumčienė, Beatričè Sipavičiūtė, Sigitas Paleckis \\ Lithuanian Sports University, Kaunas, Lithuania
}

\begin{abstract}
Background. The behaviour of physical education (PE) teachers in managing the lesson is significantly related to their life satisfaction (Bahadir, 2013). PE teachers' self-report of emotional abilities is positively associated with the educational achievements of their students and increasing teachers' self-report of emotional abilities improves the quality of physical education (Buns \& Thomas, 2016). High self-report of emotional abilities reduces the impact of work-related stress on teachers, increases their creativity in classroom activities and increases students' satisfaction with physical activities (Huang, Liu, Hsieh, \& Chang, 2015). The aim of this study was to evaluate physical education teachers' self-report of emotional abilities and subjective quality of life in comparison with teachers of other subjects, so that in the future more effective measures for improving teachers' self-report of emotional abilities and subjective quality of life could be developed.

Methods. To collect data, Schutte SSRI and SF-36 questionnaire survey was applied.

Results. We found that, according to some sub-scales, men and women were significantly $(p<.05)$ different in the estimation of their subjective quality of life. Women scored better (higher scores) than men in their physical performance, emotional state, energy/fatigue, and perceived pain. In this study, we revealed significant correlations between social skills and appraisal $(r=.305, p<.01)$, emotional well-being and appraisal $(r=.214 ; p<.05)$, and energy/fatigue and appraisal $(r=.209 ; p<.05)$. The data obtained in our study revealed that male and female teachers evaluated their ability to understand and analyze emotions and manage emotions differently $(p<.05)$.

Conclusions. Teachers' self-report of emotional abilities differed significantly by appraisal and utilization and by the subject taught, which differed in optimism, appraisal, and utilization. Significant $(p<.05)$ differences in subjective quality of life were found by gender in to physical functioning, emotional well-being, energy/fatigue, and pain. There was no significant difference found in subjective quality of life by the subject taught.
\end{abstract}

Keywords: physical education, teacher, self-report of emotional abilities, subjective quality of life.

\section{INTRODUCTION}

$\mathrm{W}$ $\mathrm{HO}$ defines subjective quality of life as the perception of individuals about their position in life, in the context of the cultural and value systems in which they live and in relation to their goals, expectations, standards and concerns (WHO, 2003).

It has been found (Bahadir, 2013) that the behavior of physical education (PE) teachers in managing the lesson is significantly related to their life satisfaction. PE teachers' self-report of emotional abilities is positively associated with the educational achievements of their students and increasing teachers' self-report of emotional abilities improves the quality of physical education (Buns \& Thomas, 2016). High self-report of emotional abilities reduces the impact of workrelated stress on teachers, increases their creativity in classroom activities and increases students' satisfaction with physical activities (Huang, Liu, Hsieh, \& Chang, 2015).

By self-determination theory, a person is born with an intrinsic motivation to explore, master, and improve his or her environment and to seek high self-report of emotional abilities when the basic 
psychological needs (relatedness, competence, and autonomy) are balanced and satisfied (Ryan \& Deci, 2004).

Satisfaction of basic psychological needs is essential for the subjective sense of well-being (Deci \& Ryan, 2002). A study (Reis, Sheldon, Gable, Roscoe, \& Ryan, 2000) has shown that the degree of satisfaction of basic needs for autonomy, competence, and relatedness leads to fluctuations in daily perceptions of perceived emotional wellbeing. People often relinquish autonomy and competence to maintain relationships that meet the need for relatedness as one of their basic psychological needs (Ryan \& Deci, 2004).

Deci, Ryan, Gagne, Leone, Usunov, and Kornazheva (2001) indicated that a desire or goal only represents a basic need if its level of satisfaction depends on the subjective level of perception of human well-being. Basic psychological needs are universal for all cultures, ages, and contexts (Deci \& Ryan, 2000), thus should be inherent for teachers in secondary schools and gymnasiums.

It has been found (Le Cornu, 2013) that if teachers are dissatisfied with the subjective quality of life, $40 \%$ of them leave the profession during their first five years of employment. Dissatisfaction with the subjective quality of life leads to the risk of psychological fatigue and less involvement of teachers in their professional activities (Brown \& Roloff, 2011). Capone and Petrillo (2016) found that dissatisfaction with subjective quality of life has a significant relationship with depression and emotional exhaustion, and is influenced by the school's psychological emotional environment.

Çevik (2017), who examined teacher satisfaction with subjective quality of life, effectiveness of education and self-report of emotional abilities, found that satisfaction with subjective quality of life and self-report of emotional abilities played an important role in teachers' job satisfaction.

As Taylor, Ntoumanis, and Standage (2008) indicate, the PE teachers' psychological need satisfaction had a positive impact on theireducational strategies, which may be factors affecting teacher motivation of students in physical education. It can also indirectly affect their motivation strategies for their students. On the other hand, Taylor, Ntoumanis, and Smith (2009) found that various aspects of the physical education context may threaten the needs of teacher autonomy, competence, and relatedness. These circumstances often determine the strategies used by PE teachers to motivate their students for physical activity and it does not create conditions for satisfaction of students' psychological needs.

Other studies (Leon \& Nunez, 2013) also revealed a positive association between the level of satisfaction of psychological needs and positive indicators of subjective quality of life, and a negative association with negative indicators of subjective quality of life. Teachers should be able to effectively assess students' basic psychological needs as indicated (Vermeulen, Castelijns, Kools, $\&$ Koster, 2012).

(Kidger et al., 2016) found that the average level of teacher subjective quality of life was lower than in the working-age population. Some felt incapable of communicating with their colleagues, feeling stressed, dissatisfied with work, and having a high degree of pragmatism, which was strongly associated with symptoms of poor subjective quality of life and depression. The research carried out by Vazi et al. (2013) suggests that the subjective quality of life is negatively related to the following factors: external locus of control, role problems, workplace pressures, and negative affect. However, subjective quality of life correlates positively with positive affect.

Self-report of emotional abilities. Self-report of emotional abilities indicates the degree to which individuals believe they are capable, significant, successful, and worthy (Marsh, 1996). Selfreport of emotional abilities is a multidimensional construct and must be weighed against the fact that levels of human competence may vary in different areas of life. An individual may underestimate their ability and performance. An adequately selfassessing individual objectively evaluates his or her abilities and capabilities, comparing them with the requirements of the environment. The self-report of emotional abilities of such individuals is close to real.

It has been found (Orth, Trzesniewski, \& Robins, 2010) that people who value themselves adequately are able to change their opinions when necessary, communicate more easily, find the job they want, or become a team leader. People with adequate self-report of emotional abilities are quieter, and they rationally solve problems in critical situations (Ionescu, Voicu, \& Ulmeanu, 2010). According to DuBois et al. (2002), increased self-report of emotional abilities makes an individual intolerant to the demands placed upon him or her by others.

Individuals with reduced self-report of emotional abilities are often sensitive to their 
personality assessments in the environment. Even when they are gifted and educated, due to low self-report of emotional abilities, they may not adequately appreciate the good opinion of others (Ionescu et al., 2010).

Self-determination theory argues that true and authentic self-report of emotional abilities is stable and assured when people are viable, fully functional and motivated when all their needs are satisfied (Ryan \& Deci, 2004). However, when selfreport of emotional abilities is a concern for people and basic psychological needs are not satisfied or balanced, self-report of emotional abilities becomes defensive.

A study by Chia-Ming, Lu-Sheng, Hsing, Yu, and Hsiu-Chin (2013) found that positive psychological capital of teachers, especially high self-report of emotional abilities, significantly influences their job satisfaction and reduces job burn-out.

Research on teachers' self-efficacy, self-report of emotional abilities, and subjective sense of happiness revealed (Erozkan, Dogan, \& Adiguzel, 2016) that initiative, effort, and self-report of emotional abilities sub-dimensions significantly correlate with life well-being assessments.

Khezerlou (2014) found that knowing the levels of teacher and student self-report of emotional abilities is useful in diagnosing their pedagogical problems when most of students are unmotivated and poorly involved in the educational process.

Sharma \& Manani's (2012) study also confirmed that there is a strong correlation between teacher self-report of emotional abilities level and job satisfaction. Higher self-report of emotional abilities is associated with higher subjective quality of life and higher levels of inner harmony (Cecen, 2008). Thus, researchers believe that self-report of emotional abilities is an important component of psychological well-being and mental health. According to the research (Cenkseven-Önder \& Sari, 2009), stress at work negatively influences people's self-report of emotional abilities.

According to Nurullach (2010), high positive self-report of emotional abilities has a positive influence on the mental health of the person and helps to maintain it. It has been revealed (Hannover, Birkner, \& Pohlmann, 2006) that those who value themselves better are more likely to affect others' ability to maintain interpersonal relationships and communicate effectively with others. It is believed (Rehman, Qingren, Latif, \& Iqbal, 2017) that psychological capital (high self-report of emotional abilities, hope, optimism, ability to quickly restore spiritual strength) positively influences the expression of emotional exhaustion of school principals.

High self-report of emotional abilities and professional training for teaching are needed to enable teachers to successfully develop their educational activities (Driel \& Berry, 2012).

It has been established (Malinauskas \& Dumčienè, 2016) that well-being and self-report of emotional abilities are related to the circumstances of life and activity during the assessment.

Hypothesis - the physical education teachers evaluate their self-report of emotional abilities and subjective quality of live better than teachers of other subjects.

\section{METHODS}

Research participants sample consisted of 28 men and 70 women, including $34 \mathrm{PE}$ teachers and 64 other subject teachers from secondary schools and gymnasiums.

Teacher self-report of emotional abilities and subjective quality of life were selected as the dependent variables of the research object, while gender and subject matter were selected as independent variables.

Instruments. The SF-36 Short Form 36 Medical Outcomes Study Questionnaire (Ware, Sherbourne, 1992) was used to assess teachers' subjective quality of life. The questionnaire contains 36 items covering eight areas of life with sub-scales: physical functioning, role limitations due to physical health, role limitation' due to emotional problems, energy/ fatigue, emotional well-being, social functioning, pain and overall health assessment. This scale was adapted to the Lithuanian population and was validated (Staniūtè, 2007).

Schutte Self-Report Inventory (SSRI) (Schutte, Malouff, 1999) was employed for teachers' selfreport of emotional abilities evaluation. The SSRI comprises 33 items, covering four areas with subscales: optimism, social skills, appraisal, utilization, which respondents need to evaluate by using a Likert 5-point scale, where 1 means "strongly disagree” and 5 -, ,strongly agree". The Lithuanian version of the SSRI shows internal consistency value 0.79 and a test-retest reliability coefficient of 0.84 for the overall questionnaire (Malinauskas \& Vazne, 2014). 
Statistical analysis. SPSS-22.0 (Statistical Package for Social Sciences for Windows) software package was used for data processing. Prior to statistical analysis, the normal distribution of quantitative variables was tested using the Shapiro Wilk test at $p<05$. Analyzing the distributions of the scale variables it was found that the distributions of all variables were not significantly distant from the normal distribution, therefore parametric criteria were chosen for the analysis. The Cronbach's alpha (for SF-36 questionnaire $\alpha=.785$ and for Schutte $-\alpha=.689$ ) reliability factor was used to test the reliability and compatibility of the scales. Mean values and standard deviations of response estimates were calculated, Fisher's criterion for variances and Student's t test were used to compare two independent samples. Pearson's correlation coefficient was used to test the relationships between variables. Significance level $p<.05$ was adopted in the analysis.

\section{RESULTS}

Estimates of subjective quality of life for male and female teachers are presented in Table 1.

There were no statistically significant differences in teachers' subjective quality of life in relation to the subject taught $(p>.05)$.

The teachers' self-report of emotional abilities estimates by gender are shown in Table 2 .

Teachers' self-report of emotional abilities estimates by subject taught are shown in Table 3 .

Data on the relations between score estimates of teacher subjective quality of life and self-report of emotional abilities are presented in Table 4.

Table 1. Teacher subjective quality of life estimates by gender (Scores)

\begin{tabular}{|c|c|c|c|c|c|c|c|c|}
\hline \multirow{2}{*}{ Sub-scale } & \multicolumn{2}{|c|}{ Men $(n=28)$} & \multicolumn{2}{|c|}{ Women $(n=70)$} & \multirow{2}{*}{$F$} & \multirow{2}{*}{$p$} & \multirow{2}{*}{$t$} & \multirow{2}{*}{$p$} \\
\hline & $\mathbf{M}$ & SD & $\mathbf{M}$ & SD & & & & \\
\hline Physical functioning & 66.61 & 25.77 & 87.15 & 14.84 & $26.56 * *$ & $<.05$ & $-4.844 * *$ & $<.05$ \\
\hline Role limitations due to physical health & 76.25 & 23.21 & 76.54 & 36.94 & $4.619 *$ & $<.05$ & -0.038 & $>.05$ \\
\hline Role limitations due to emotional problems & 61.07 & 28.47 & 70.77 & 39.75 & $7.817 * *$ & $<.05$ & -1.167 & $>.05$ \\
\hline Social functioning & 74.07 & 15.86 & 79.69 & 20.23 & 0.726 & $>.05$ & -1.303 & $>.05$ \\
\hline Emotional well-being & 66.39 & 13.60 & 73.15 & 14.70 & 0.329 & $>.05$ & $-2.08^{*}$ & $<.05$ \\
\hline Energy/fatigue & 59.63 & 11.97 & 70.23 & 18.61 & $4.50 *$ & $<.05$ & $-2.772 * *$ & $<.05$ \\
\hline Pain & 65.29 & 27.39 & 78.00 & 23.70 & 1.803 & $>.05$ & $-2.263 *$ & $<.05$ \\
\hline Overall health assessment & 64.64 & 22.23 & 63.25 & 20.34 & 0.668 & $>.05$ & 0.295 & $>.05$ \\
\hline
\end{tabular}

Notes. $(M, S D)$ - mean and standard deviation, ${ }^{*} p<.05,{ }^{*} p<.01$.

Table 2. Teacher self-report of emotional abilities estimates by gender (scores)

\begin{tabular}{|c|c|c|c|c|c|c|c|c|}
\hline \multirow{2}{*}{ Sub-scale } & \multicolumn{2}{|c|}{$\operatorname{Men}(n=28)$} & \multicolumn{2}{|c|}{ Women $(n=70)$} & \multirow{2}{*}{$F$} & \multirow{2}{*}{$p$} & \multirow{2}{*}{$t$} & \multirow{2}{*}{$p$} \\
\hline & $\mathbf{M}$ & SD & $\mathbf{M}$ & SD & & & & \\
\hline Optimism & 4.32 & 0.946 & 4.049 & 0.498 & $32.96 * * *$ & $<.05$ & 1.784 & $>.05$ \\
\hline Social skills & 4.19 & 0.514 & 3.99 & 0.594 & 0.00 & $>.05$ & 1.501 & $>.05$ \\
\hline Appraisal & 3.912 & 0.508 & 3.547 & 0.406 & 1.938 & $>.05$ & $3.611 * *$ & $<.05$ \\
\hline Utilization & 4.13 & 0.572 & 3.65 & 0.569 & 0.212 & $>.05$ & $3.687 * * *$ & $<.05$ \\
\hline
\end{tabular}

Notes. $(M, S D)-$ mean and standard deviation, ${ }^{*} p<.05, * * p<.01, * * * p<.001$. 
Table 3. Teacher self-report of emotional abilities estimation subject taught (scores)

\begin{tabular}{|l|c|c|c|c|c|c|c|c|}
\hline \multirow{2}{*}{ Sub-scale } & \multicolumn{2}{|c|}{ Physical education $(\boldsymbol{n}=\mathbf{3 4})$} & \multicolumn{2}{|c|}{ Others subjects $(\boldsymbol{n}=\mathbf{6 4})$} & \multirow{2}{*}{$\boldsymbol{F}$} & $\boldsymbol{p}$ & $\boldsymbol{t}$ & $\boldsymbol{p}$ \\
\cline { 2 - 9 } & $\mathbf{M}$ & $\mathrm{SD}$ & $\mathbf{M}$ & $\mathrm{SD}$ & & & \\
\hline Optimism & 4.32 & 0.872 & 4.03 & 0.512 & $20.74 * * *$ & $<.05$ & $1.994^{*}$ & $<.05$ \\
\hline Social skills & 4.16 & 0.561 & 3.99 & 0.579 & 0.623 & $>.05$ & -1.363 & $>.05$ \\
\hline Appraisal & 3.55 & 0.373 & 3.85 & 0.558 & $8.785 * *$ & $<.05$ & $-2.971^{* *}$ & $<.05$ \\
\hline Utilization & 4.00 & 0.636 & 3.66 & 0.561 & 1.542 & $>.05$ & $-2.659^{* *}$ & $<.05$ \\
\hline
\end{tabular}

Notes. $(M, S D)-$ mean and standard deviation, $* \mathrm{p}<.05, * * \mathrm{p}<.01, * * * \mathrm{p}<.001$.

Table 4. Correlations between scores coefficients of teacher subjective quality of life and self-report of emotional abilities

\begin{tabular}{|c|c|c|c|c|c|}
\hline Sub-scale & $\begin{array}{l}r \\
p\end{array}$ & Optimism & Social skills & Appraisal & Utilization \\
\hline Physical functioning & $\begin{array}{l}\mathrm{r} \\
\mathrm{p}\end{array}$ & $\begin{array}{l}-.096 \\
>.05\end{array}$ & $\begin{array}{l}-.192 \\
>.05\end{array}$ & $\begin{array}{c}.061 \\
>.05\end{array}$ & $\begin{array}{l}-.11 \\
>.05\end{array}$ \\
\hline Role limitations due to physical health & $\begin{array}{l}\mathrm{r} \\
\mathrm{p}\end{array}$ & $\begin{array}{r}.066 \\
>.05\end{array}$ & $\begin{array}{c}.037 \\
>.05\end{array}$ & $\begin{array}{c}.053 \\
>.05\end{array}$ & $\begin{array}{c}.091 \\
>.05\end{array}$ \\
\hline Role limitations due to emotional problems & $\begin{array}{l}\mathrm{r} \\
\mathrm{p}\end{array}$ & $\begin{array}{l}-.03 \\
>.05\end{array}$ & $\begin{array}{l}-.043 \\
>.05\end{array}$ & $\begin{array}{l}-.045 \\
>.05\end{array}$ & $\begin{array}{l}-.098 \\
>.05\end{array}$ \\
\hline Social functioning & $\begin{array}{l}\mathrm{r} \\
\mathrm{p}\end{array}$ & $\begin{array}{c}.169 \\
>.05\end{array}$ & $\begin{array}{c}.67 \\
>.05\end{array}$ & $\begin{array}{c}.305^{* *} \\
<.01\end{array}$ & $\begin{array}{c}.046 \\
>.05\end{array}$ \\
\hline Emotional well-being & $\begin{array}{l}\mathrm{r} \\
\mathrm{p}\end{array}$ & $\begin{array}{c}.151 \\
>.05\end{array}$ & $\begin{array}{l}-.77 \\
>.05\end{array}$ & $\begin{array}{l}.214^{*} \\
<.05\end{array}$ & $\begin{array}{l}-.133 \\
>.05\end{array}$ \\
\hline Energy/fatigue & $\begin{array}{l}\mathrm{r} \\
\mathrm{p}\end{array}$ & $\begin{array}{l}-.47 \\
>.05\end{array}$ & $\begin{array}{l}-.006 \\
>.05\end{array}$ & $\begin{array}{l}.209 * \\
<.05\end{array}$ & $\begin{array}{l}-.037 \\
>.05\end{array}$ \\
\hline Pain & $\begin{array}{l}r \\
p\end{array}$ & $\begin{array}{c}.033 \\
>.05\end{array}$ & $\begin{array}{l}-.044 \\
>.05\end{array}$ & $\begin{array}{l}-.05 \\
>.05\end{array}$ & $\begin{array}{l}-.074 \\
>.05\end{array}$ \\
\hline Overall health assessment & $\begin{array}{l}r \\
p\end{array}$ & $\begin{array}{l}-.08 \\
>.05\end{array}$ & $\begin{array}{c}.127 \\
>.05\end{array}$ & $\begin{array}{c}.081 \\
>.05\end{array}$ & $\begin{array}{l}-.001 \\
>.05\end{array}$ \\
\hline
\end{tabular}

Notes. $r$ - Pearson correlation coefficient, $p$ - significance level, $* p<.05, * * p<.01$.

\section{DISCUSSION}

This study was limited to the teachers' assessment of their subjective quality of life in the health dimension, which included eight subjective quality of life indicators and self-report of emotional abilities in four indicators.

The hypothesis was partially confirmed, with significant differences found only in some subscales of subjective quality of life and self-report of emotional abilities.
In this study, we found that, according to some sub-scales, men and women were significantly different in the estimation of their subjective quality of life. Women scored better (higher scores) than men on their physical performance, emotional state, energy/fatigue, and perceived pain. Men scored higher on their overall health assessment, but the difference in estimates was not significant. Physical education teachers' self-report of emotional 
abilities was higher than that of other teachers of subjects, but the differences were significant only in the appraisal and utilization sub-scales.

According to the Price and McCallum's (2015) study, factors of activity and living environment influence the individual's perceived subjective wellbeing and relevance and context. Thus, in addition to the subjective assessment of their subjective quality of life, the teachers should consider themselves in a broader perspective: being physically fit and energetic, happy, learning, networking, and fit for the profession.

Researching the subjective quality of life of physical education teachers by gender, Brazilian researchers (Both et al., 2017) found that men were more satisfied with their subjective quality of life than women. Men were more satisfied with work, valued their relationships with colleagues and had better control over stress, while women reported significantly better nutrition skills.

The results of a study on educators conducted by Rogach, Ryabova, and Frolova (2017) revealed that the psychological component of subjective quality of life was significantly influenced by the stability of working and contract conditions, the increase in the speed of pedagogical activity and shortcomings in scheduling. Motivational profile factors that cause differences in values within the school community, stable dominance of negative emotions, masking of uncertainty in one's ability, systematic lack of peer support, increased anxiety, and increased likelihood of conflict between educators were also significantly influenced.

Our study revealed that women valued their emotional well-being better than men, with $73.15 \pm$ 14.7 and $66.39 \pm 13.6$ points, respectively.

According to other researchers, teachers' emotional well-being, emotional commitment to the organization positively influences the mental well-being of teachers' lives (McInerney, Ganotice, King, Morin, \& Marsh, 2015).

It has been found (Väisänen, Pietarinen, Pyhältö, Toom, \& Soini, 2017) that the psychological component of young teachers' subjective quality of life was significantly influenced by the emotional support of their colleagues.

Researchers Hobson and Maxwell (2017) believe that the subjective quality of life of young early-stage teachers is significantly determined by the level of satisfaction of basic psychological needs - competence, connectivity and autonomy. These researchers have revealed that meeting these three basic psychological needs is a necessary but not a prerequisite for optimization of the wellbeing of early career teachers, which is related to a broader spectrum of environmental factors.

It has been found (Tabancali, 2016) that teachers' subjective quality of life assessment is significantly influenced by their social connections, emotional state, and internal satisfaction, which is significantly predicted by social communication. Emotional states and social relationships are significantly related to external satisfaction, but only social communication significantly predicts external job satisfaction.

Physical education teachers often find themselves at a disadvantage in the evaluation of self-report of emotional abilities and their subjective quality of life, since physical education is not one of the core curriculum courses from the principals' and other teachers' points of view. As Norris et al. (2017) revealed, the priority of the physical education subject is low, the physical education teacher assessment system is not properly positioned in relation to other subject teachers and physical education teachers are not convinced that their assessor can provide a fair and appropriate assessment.

Our study found no significant differences between physical education and other subject teachers in any of the eight identified subjective quality of life measures. In our opinion, this is a very interesting result, as physical education is often considered a secondary subject in schools and the number of other classes are increased by reducing the number of physical education classes.

Liu, Wang, Shen, Li, and Wang (2015), who studied the subjective quality of life of teachers in one of the Chinese provinces with the SF36 questionnaire, found low ratings of teachers' physical functioning $(71.43 \pm 14.7)$ and emotional well-being (65.46 \pm 16.55$)$. In our sample of teachers we found higher mean estimation values than Liu et al. (2015), in scales of physical functioning ( $81.15 \pm$ 17.12) and emotional well-being $(70.9 \pm 14.32)$, respectively.

In this study, we revealed significant correlations between social skills and appraisal $(r=.305, p<$ $.01)$, emotional well-being and appraisal $(r=.214$, $p<.05)$, and energy/fatigue and appraisal $(r=.209$, $p<.05)$.

The data obtained in our study revealed that male and female teachers evaluate their ability 
to understand and analyze emotions and manage emotions differently $(p<.05)$. Erford, Lowe, and Chang (2011) refer to the importance of teacher self-report of emotional abilities and its level of relationship to student educational achievement. Higher self-report of emotional abilities is associated with higher subjective quality of life satisfaction and higher levels of inner harmony (Cecen, 2008). According to Hannover, Birkner, and Pohlmann (2006), individuals with good self-report of emotional abilities are more likely to be liked by others, which may influence their ability to maintain interpersonal relationships and communicate effectively with other people.

Overall, physical education teachers rank their self-report of emotional abilities higher than teachers of other subjects, with a score of 4.01 and 3.88 , respectively. Physical education teachers rated their ability to rely on their emotional experiences, evaluate and express emotions, and manage emotions better than those of other subjects. Other teachers, meanwhile, appreciated their ability to evaluate and express emotions better.

According to Nurullach (2010), high positive self-report of emotional abilities positively influences human mental health and helps to maintain it. This is partly supported by the data of our study. Physical education teachers with higher self-report of emotional abilities than teachers of other subjects had a higher overall health score (68.13 and 61.1 points, respectively).

\section{CONCLUSIONS}

1. Teachers' self-report of emotional abilities differed significantly by gender according to two of the four sub-scales: appraisal and utilization. By the subject course they differed according to three sub-scales: optimism, appraisal, and utilization.

2. Significant $(p<.05)$ differences in subjective quality of life by gender were revealed in the sub-scales of physical functioning, emotional well-being, energy/fatigue, and pain. There was no significant difference found in subjective quality of life by the subject taught mean scores $(p>.05)$, although physical education teachers rate their subjective quality of life better than teachers of other subjects according to limitations due to physical health and other subjects' teachers in accordance with social skills.

3. Teachers' self-report of emotional abilities and subjective quality of life assessments are weak, but some sub-indicators are significantly related. The following significant $(p<.05)$ relationships between teachers' subjective quality of life and self-report scores of emotional abilities were found for the following scales: social skills and appraisal, emotional well-being and appraisal, energy/fatigue and appraisal.

\section{REFERENCES}

Bahadir, Z. (2013). A research on the class management behaviors and life satisfaction of physical education teachers. International Journal of Academic Research, Part B, 5(4), 170-175. doi: 10.7813/2075-4124.2013/54/B.25

Both, J., Borgatto. A. F., Lemos, C. A. F., Ciampolini, V., \& do Nascimento, J. V. (2017). Physical education teachers' wellbeing and its relation with gender. Motricidade, 13(4), 23-32. doi: 10.6063/motricidade. 10165

Brown, L. A., \& Roloff, M. E. (2011). Extra-role time, burnout, and commitment: The power of promises kept. Business Communication Quarterly, 74(4), 450474. doi: 10.1177/1080569911424202

Buns, M. T., \& Thomas, K. T. (2016). The effect of a virtual standards-based training program on physical education teacher self-efficacy. International Journal of Physical Education, Sports and Health, 3(3), 485-493.

Capone, V., \& Petrillo, G. (2016). Teachers' perceptions of fairness, well-being and burnout: A contribution to the validation of the Organizational Justice Index by
Hoy and Tarter, International Journal of Educational Management, 30(6), 864-880.

Cecen, A. R. (2008). Sense of coherence, family sense of coherence and self-esteem in predicting life satisfaction among university students. Journal of Theory and Practice in Education, 4(1), 19-30.

Cenkseven-Önder, F., \& Sari, M. (2009). The quality of school life and burnout as predictors of subjective wellbeing among teachers. Educational Sciences: Theory \& Practice, 9(3), 1223-1236.

Çevik, G. B. (2017). The roles of life satisfaction, teaching efficacy, and self-esteem in predicting teachers' job satisfaction. Universal Journal of Educational Research, 5(3), 338-346. doi: 10.13189/ujer.2017.050306

Chia-Ming, C., Lu-Sheng, C., Hsing, Yu. L., \& HsiuChin, H. (2013). The relationship between psychological capital and job satisfaction of university physical education teachers in Taiwan: Job-stressors and jobburnout as mediators. Retrieved from http://tweb.cjcu. edu.tw/journal_abstract/2012_11_26_09_13_15.927.pdf 
Deci, E. L., Ryan, R. M., Gagne', M., Leone, D. R., Usunov, J., \& Kornazheva, B. P. (2001). Need satisfaction, motivation, and well-being in the work organizations of a former Eastern Bloc country. Personality and Social Psychology Bulletin, 27, 930-942.

Deci, E., \& Ryan, R. M. (2002). Handbook of selfdetermination research. Rochester: University of Rochester Press.

Deci, E. L., \& Ryan, R. M. (2000). The "what" and "why" of goal pursuits: Human needs and the selfdetermination of behaviour. Psychological Inquiry, 11, 227-268.

Driel, J. H., \& Berry, A. (2012). Teacher professional development focusing on pedagogical content knowledge. Educational Researcher, 41(1), 26-28.

DuBois, D. L., Burk-Braxton, C., Swenson, L. P., Tevendale, H. D., Lockered, E. M., \& Moran, B. L. (2002). Getting by with a little help from self and others: Self-esteem and social support as resources during early adolescence. Developmental Psychology, 38, 822-839.

Erozkan, A., Dogan, U., \& Adiguzel, A. (2016). Selfefficacy, self-esteem, and subjective happiness of teacher candidates at the pedagogical formation certificate program. Journal of Education and Training Studies, 4(8), 72-82.

Hannover, B., Birkner, N., \& Pohlmann, C. (2006). Ideal selves and self-esteem in people with independent or interdependent self-construal. European Journal of Social Psychology, 36, 119-133.

Hobson, A. J., \& Maxwell, B. (2017). Supporting and inhibiting the well-being of early career secondary school teachers: Extending self-determination theory. British Educational Research Journal, 43(1), 168-191. doi: 10.1002/berj.3261

Huang, H.-Ch., Liu, L.-W., Hsieh, H.-H., \& Chang, Ch.-M. (2015). Relationships among physical education teachers' psychological capital, work stress, and creative teaching. Journal of Baltic Science Education, 14(6), 744-752.

Ionescu, S., Voicu, S., \& Ulmeanu, A. (2010). The relationship between self-esteem and physical exercise in women sports practice. Science. Movement and Health, 10(2), 246-250.

Jang, H., Reeve, J., Ryan, R. M., \& Kim, A. (2009). Can self-determination theory explain what underlies the productive, satisfying learning experiences of collectivistically oriented Korean students? Journal of Educational Psychology, 101(3), 644-661.

Khezerlou, E. (2014). Evaluation of professional selfesteem among EFL teachers and students at Mevlana university. Journal of History Culture and Art Research, 3(3), 76-86.

Kidger, J., Brockman, R., Tilling, K., Campbell, R., Ford, T., Araya, R., King, M., \& Gunnell, D. (2016). Teachers' wellbeing and depressive symptoms, and associated risk factors: A large cross-sectional study in English secondary schools. Journal of Affective Disorders, 192, 76-82.
Le Cornu, R. (2013). Building early career teacher resilience: The role of relationships. Australian Journal of Teacher Education, 38(4), 1-16.

León, J., \& Núñez, J. L. (2013). Causal ordering of basic psychological needs and well-being. An International and Interdisciplinary Journal for Quality-of-Life Measurement, 114(2), 243-253.

Liu, Ch., Wang, S., Shen, X., Li, M., \& Wang, L. (2015). The association between organizational behavior factors and health-related quality of life among college teachers: A cross-sectional study. Health and Quality of Life Outcomes, 13(85), 1-12. doi: 10.1186/s12955-015-0287-4

Malinauskas, R., \& Dumciene, A. (2016). Psychological wellbeing and self-esteem in students across the transition between secondary school and university: A longitudinal study. Psichologija, 50, 1-16. doi: 10.2298/ psi160506003m

Malinauskas, R., Vazne, Z. (2014). Emotional intelligence among Lithuanian and Latvian student athletes. Education. Physical Training. Sport, 2(93), 29-33.

Marsh, H. W. (1996). Positive and negative global self-esteem: A substantively meaningful distinction or artifactors? Journal of Personality and Social Psychology, 70, 810-819.

McInerney, D. M., Ganotice, F. A., King, R. B., Morin, A. J. S., \& Marsh, H. W. (2015). Teachers' commitment and psychological well-being: Implications of self-beliefs for teaching in Hong Kong. Educational Psychology. An International Journal of Experimental Educational Psychology, 35, 926-945.

Norris, J., van der Mars, H., Kulinna, P., AmreinBeardsley, A., Kwon, J., \& Hodges, M. (2017). Physical education teacher perceptions of teacher evaluation. The Physical Educator, 74, 41-62. doi.org/10.18666/TPE2017-V74-I1-6882

Nurullah, A. (2010). Gender differences in distress: The mediating influence of life stressors and psychological resources. Asian Social Science, 6(5), 27-37.

Orth, U., Trzesniewski, K. H., \& Robins, R. W. (2010). Self - esteem development from young adulthood to old age: A cohort - sequential longitudinal study. Journal of Personality and Social Psychology, 98(4), 645-658.

Price, D., \& McCallum, F. (2015). Ecological influences on teachers' well-being and "fitness". Asia-Pacific Journal of Teacher Education, 43(3), 195-209.

Rehman, S., Qingren, C. A. O., Latif, Y., \& Iqbal, P. (2017). Impact of psychological capital on occupational burnout and performance of faculty members. International Journal of Educational Management, 31(4), 1-17. doi.org/10.1108/IJEM-01-2016-0011

Reis, H. T, Sheldon, K. M., Gable, S. L., Roscoe, J., \& Ryan, R. M. (2000). Daily well-being: The role of autonomy, competence, and relatedness. Personality and Social Psychology Bulletin, 26, 419-435. doi. org/10.1108/IJEM-02-2015-0013

Rogach, O., Ryabova, T. M., \& Frolova, E. V. (2017). Social Factors of Mental Well-Being Violation Among High School Teachers. European Journal of 
Contemporary Education, 6(4), 787-796. doi: 10.13187/ ejced.2017.4.787

Ryan, R. M., \& Deci, E. L. (2004). Autonomy is no illusion: Self-determination theory and the empirical study of authenticity, awareness, and will. In J. Greenberg, S. L. Koole, \& T. Pyszczynski (Eds.), Handbook of experimental existential psychology (pp. 449-479). New York: The Guilford Press.

Ryan, R., \& Deci, E. (2001). On happiness and human potentials: A review of research on hedonic and eudaimonic well-being. Annual Review of Psychology, $52,141-166$.

Schutte, N. S., Malouff, J. M. (1999). Measuring emotional intelligence and related constructs. New York: Edwin Mellen Press.

Sharma, S., \& Manani, P. (2012). Relationship between self-esteem and job satisfaction among teachers. Journal of Psychosomatic Research, 7(2), 291-296.

Staniūtè, M. (2007). Su sveikata susijusios gyvenimo kokybès vertinimas naudojant SF-36 klausimyną. Biologine psichiatrija ir psichofarmakologija, 9(1), 22-25.

Taylor, I. M., Ntoumanis, N., \& Smith, B. (2009). The social context as a determinant of teacher motivational strategies in physical education. Psychology of Sport and Exercise, 10, 235-243.

Taylor, I. M., Ntoumanis, N., \& Standage, M. (2008). A self-determination theory approach to understanding the antecedents of teachers' motivational strategies in physical education. Journal of Sport \& Exercise Psychology, 30, 75-94.

The WHOQoL Group. (1993). Study protocol for the World Health Organization Project to develop a Quality of Life Assessment Instrument (WHOQoL). Quality of Research, 2, 159-153.

Väisänen, S., Pietarinen, J., Pyhältö, K., Toom, A., \& Soini, T. (2017). Social support as a contributor to student teachers' experienced well-being. Research Papers in Education, 32, 41-55.

Vazi, M. L. M., Ruiter, R. A. C., Van den Borne, B., Martin, G., Dumont, K., \& Reddy, P. S. (2013). The relationship between wellbeing indicators and teacher psychological stress in Eastern Cape public schools in South Africa. SA Journal of Industrial Psychology, 39(1), $1-10$.

Vermeulen, M., Castelijns, J., Kools, Q., \& Koster, B. (2012). Measuring student teachers' basic psychological needs. Journal of Education for Teaching, 38(4), 453467.

Ware, J. E., \& Sherbourne, C. D. (1992). The MOS 36item short form health survey (SF-36). I. Conceptual framework and item selection. Medical Care, 30(6), 473-483.

WHO. (2003). WHO definition of health. Retrieved from http://pnf.org/Definitions_of_Health_C.pdf 